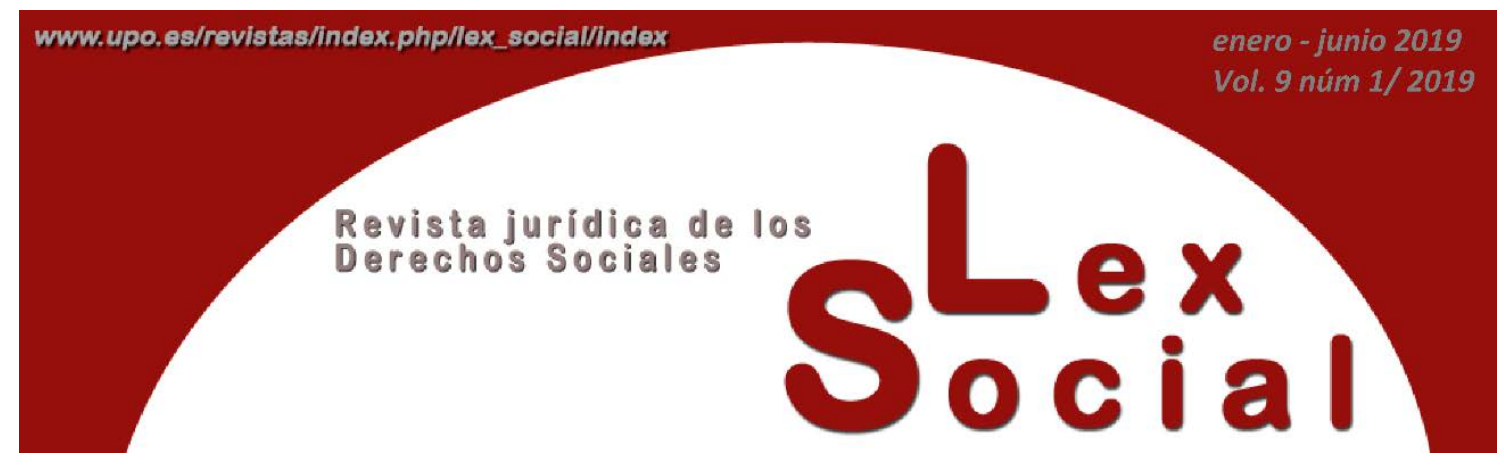

PRESENTACIÓN NÚMERO 9-1 (2019)

\title{
HOMENAJE PROFESOR MANUEL JOSÉ TEROL BECERRA, VALEDOR Y GUARDIÁN DE LOS DERECHOS SOCIALES
}

\author{
Carmen Salcedo Beltrán \\ Jean Michel Belorgey \\ Antonio Torres del Moral \\ María Holgado González \\ Luis Jimena Quesada
}

En mi condición de codirectora de la Revista Lex Social: revista de derechos sociales, comienzo la Presentación del número pidiendo disculpas, en primer lugar, a todos los lectores y seguidores de la misma por el retraso en la aparición del número.

Tradicionalmente, el ejemplar correspondiente al primer semestre suele publicarse a lo largo del mes de enero. De forma excepcional, ha tenido que retrasarse al producirse la triste noticia del fallecimiento de su fundador y Catedrático de Derecho Constitucional, el profesor Manuel Terol Becerra. Tan inesperado y luctuoso suceso, producido a finales del año pasado, unido al deseo de los compañeros y amigos de rendirle un homenaje, me llevaron a adoptar la decisión de posponer la publicación unos meses, en la medida en que resultaba imposible acometerlo de mantenerse la fecha de aparición habitual.

Tras esta explicación, como se ha apuntado, el número se dedica en su totalidad a nuestro querido amigo, agradeciendo, a continuación, a todos los que han participado en el mismo el esfuerzo que han realizado puesto que son numerosos los compromisos previos que se tienen asumidos a corto, medio y largo plazo y que dificultan de forma considerable la asunción de otros que puedan surgir. En esta presentación, me limitaré a referenciar brevemente, la faceta del homenajeado en cuanto a la creación de la revista, dejando a los compañeros que también participan, la relativa a la vertiente docente e investigadora. 
Gracias a la colaboración de un equipo guiado por el profesor Terol, la revista se creó en el año 2011 con la finalidad de dar difusión a los derechos sociales y las necesidades de la sociedad en este sentido. Para ello, se consideró que el marco electrónico en abierto permitiría llegar a un público muy amplio y convertirse en una herramienta útil para los juristas, la comunidad académica y todas aquellas personas que quisieran tener conocimiento o acercarse al debate.

A finales de 2014, el profesor Terol me atribuyó el honor de capitanearla a su lado, siendo un enorme reto y una gran responsabilidad que asumí y espero estar desarrollando de forma satisfactoria. Si bien el trabajo es intenso, el progreso de la revista para convertirse paulatinamente en un referente $y$, con ello, alcanzar la finalidad con la que se creó, es evidente e incontestable, como se constata en las numerosas consultas y reenvíos que se realizan por centros y universidades de todo el mundo.

Por ello, mis líneas en esta presentación van dirigidas preferentemente a manifestar públicamente a mi querido amigo Manolo mi más sincero agradecimiento por encargarme este reto que confío en seguir desempeñando con rigurosidad, debiendo mencionar que la consecución del mismo no sería posible sin el eficaz e inestimable respaldo y apoyo del responsable del Servicio de Publicación Digital de la Biblioteca de la Universidad Pablo de Olavide.

\title{
PAROLES EN HOMMAGE À MANOLO TEROL
}

\author{
JEAN-MICHEL BELORGEY \\ Presidente de la Comisión Central de Ayuda Social y Miembro del Consejo de Estado \\ francés \\ Ex Presidente del Comité Europeo de Derechos Sociales del Consejo de Europa
}

Manolo Terol, dont la disparition prématurée m’a beaucoup affligé, ne m’était pas assez intimement connu, faute pour moi d'avoir enquêté sur son parcours et ses œuvres, pour que je sois en état de rendre un hommage éclairé à sa contribution à l’intelligence, à la défense et à la promotion du droit social. Ses qualités d'organisateur de reconcentres internationales, assorties d'une exceptionnelle hospitalité matérielle et intellectuelle, de provocateur éclairé, sont en revanche de celles que je n’oublierai jamais. A défaut d'être pour l'instant en état de fournir une contribution vraiment digne de celle qu'appelle la conservation de sa mémoire, j’ai exhumé le texte de la conférence prononcée à Tanger 
dans le cadre d'une rencontre qu'il avait, avec Luis Jimena Quesada, souhaité organiser dans cette ville en vue de:

- faire valoir les mérites de la Charte sociale du Conseil de l’Europe et du Comité européen des droits sociaux, son organe de régulation, de monitoring comme il se dit sous l'insupportable dictature linguistique anglo-saxonne, et les menaces pesant sur cet effort ;

- faire ressortir aussi ce en quoi tout cela concernait nos hôtes marocains.

J’ai été profondément marqué par la façon comiquement admirative et résolument ironique dont il a salué mon intervention en qualité de membre du Conseil d'Etat français, avec amitié, car il ne m'assimilait pas, Dieu merci, à l'institution dont j'étais issu, pas plus que sa profonde amitié pour le peuple du pays qui nous accueillait et dont sa femme était issue ne lui laissait d'illusions sur les dérives imposées ou consenties auxquelles, de concert avec d'autres pays arabo-musulmans, ou de façon singulière, il était enclin à s’abandonner.

A la différence des cohortes de juristes, politologues, et autres experts en différentes catégories de droit social, Manolo n'était pas dupe. Et ne répugnait pas à l'avouer, ou à le faire valoir. Ce n'est pas là une manière facile d'être au monde. Cela ne paraissait pas affecter sa bonne humeur, son sens de la convivialité. Mais qui pourrait jurer qu'il n’y a pas là une source d'usure?

A LA MEMORIA DE MANOLO TEROL

ANTONIO TORRES DEL MORAL Catedrático Emérito de Derecho Constitucional UNED

Desde que tuve la fortuna de conocer a Manuel Terol, a Manolo, ya no dejamos de tratarnos con asiduidad no sólo por compartir disciplina académica, sino por todo lo demás: porque me introdujo en el mundo de los derechos sociales, al que después he dedicado buena parte de mis escasas energías, por su sinceridad, por su sentido de la amistad, por su espíritu de trabajo, por su jovialidad, por su clara inteligencia, por su entrega a la profesión, por la mutua colaboración en proyectos interesantes, por su alegría de vivir y por la asombrosa dignidad con la que siempre conllevó sus problemas.

Social como el Derecho que estudiaba, cabal con los amigos que tenía, cordial con los alumnos que enseñaba, 
jovial pese a la herida que sufría.

Manuel, hermano, amigo, te seguimos queriendo.

\section{A MANOLO TEROL, PROFESOR Y COMPAÑERO}

MARÍA HOLGADO GONZÁLEZ

Profesora Titular de Derecho Constitucional

Universidad Pablo de Olavide

El Profesor Manuel J. Terol Becerra dirigió, durante los últimos doce años, el Área de Derecho Constitucional de la Universidad Pablo de Olavide, que había puesto en marcha su compañero y mi director de Tesis, el Prof. Antonio J. Porras Nadales, en 1998. Previamente, el Prof. Terol había ocupado la Cátedra de Derecho Constitucional en la Universidad de Huelva y, años antes, había impartido docencia en el Departamento de Derecho Constitucional de la Universidad de Sevilla, compartiendo despacho ambos en el imponente edificio de la Antigua Fábrica de Tabacos.

Precisamente, fue en las aulas de la Facultad de Derecho de la Universidad hispalense donde conocí a Manuel Terol, mucho antes de que él me conociera a mí. Recuerdo aún, como si fuera ayer, el día en que apareció en clase y, con mostrada satisfacción, nos anunciaba la reciente paternidad de su compañero y amigo José $\mathrm{M}^{\mathrm{a}}$ Morales Arroyo, nuestro profesor de Derecho Constitucional en el cuarto curso de la licenciatura al que venía a sustituir. Comenzó entonces, acto seguido, una brillante clase magistral sobre la eficacia horizontal de los derechos fundamentales que no nos dejó indiferentes.

Y es que Manuel Terol se caracterizaba por saber captar la atención del auditorio, a golpe de frase lapidaria, y de un tono conscientemente provocador que acompañaba de esa sonrisa socarrona que todos los que lo conocimos asociamos a su recuerdo. Pero donde más disfrutaba como profesor era en los seminarios y grupos docentes reducidos, donde fomentaba el autoaprendizaje, el debate y la discusión. Lo pude constatar dos años más tarde, como alumna suya en el Doctorado en Derecho Público de la Universidad de Sevilla. Sabía crear un ambiente cercano y distendido con su alumnado y transformar los 
cursos en auténticas sesiones de debate y comentario de jurisprudencia constitucional, que podían concluir, incluso, con un almuerzo de cuscús en casa de alguno de nosotros.

Esa proximidad en el trato con sus alumnos y alumnas la mantuvo hasta el final de su vida. Su amplia trayectoria investigadora y la multitud de proyectos académicos en los que se embarcaba no le hicieron abandonar su entusiasmo por la docencia, que volcaría, sobre todo, en los estudios de máster y doctorado y en la dirección de Tesis Doctorales.

Su cercanía también la ejercía como director y compañero del área de Derecho Constitucional en la Universidad Pablo de Olavide. Gustaba de celebrar las reuniones al aire libre, en la terraza de la cafetería de la universidad (huyendo, tal vez, de las restricciones de una ley antitabaco que detestaba, por más que intentábamos convencerle de sus beneficios) y que prolongaba sin mirar el reloj. Gran conversador, nos mostraba su faceta más humana, y nos hablaba de su amplia colección de pajaritas que heredó de su padre y con las que le rendía homenaje y de su afición por las estilográficas, de las que hacía tan buen uso con una cuidadísima caligrafía.

Junto a tantos entrañables recuerdos, a sus enseñanzas y a su obra investigadora, Manolo Terol me ha dejado al frente de un extraordinario equipo de profesores que logró formar en la Universidad Pablo de Olavide y con los que tengo la inmensa suerte de trabajar, día a día, por lo que le quedo inmensamente agradecida.

\title{
SEMBLANZA EN MEMORIA DE MANUEL J. TEROL BECERRA: EL PROFESOR TEROL Y LA MILITANCIA A FAVOR DE LOS DERECHOS SOCIALES
}

\author{
LUIS JIMENA QUESADA \\ Catedrático de Derecho Constitucional \\ Universitat de València
}

\section{Empezando por lo primero: la dignidad en el centro de los derechos sociales como eje de la vivencia personal y el compromiso humanista del Profesor Terol}

Conocí al Prof. Terol con motivo de una visita que realizó a la Facultad de Derecho de Valencia hace unas dos décadas para impartir una brillante conferencia sobre el derecho a la inviolabilidad el domicilio, en la que no enfatizó la faceta cívico-política, sino la social relacionada con la protección ambiental sobre la que él ha redactado unas páginas 
excelentes en diversos libros y revistas ${ }^{1}$, haciéndose eco de los apuntes evolutivos del TEDH. Se inspiraba en una "interpretación verde" del CEDH que ganaba fuerza con la famosa STEDH López Ostra c. España de 1994 y que ponía el acento en la indivisibilidad evocada por la clásica STEDH Airey c. Irlanda de 1979, así como en las obligaciones positivas que pesan sobre los poderes públicos para procurar la efectividad de los derechos incluso en el marco de las relaciones entre particulares. Se trataba de una “interpretación verde” y de unos principios sobre la protección de los derechos fundamentales que se fueron consolidando en otros casos contra España (por ejemplo, diez años después mediante la STEDH Moreno Gómez de 2004).

Esa idea de indivisibilidad y de obligación positiva (en suma, de buena fe y efecto útil) en pro de la efectividad de los derechos humanos, y en especial de los derechos sociales, siempre le sedujo. Con semejante filosofía, recuerdo discusiones con él cuando redactamos en coautoría nuestro trabajo titulado "Reflexiones sobre la constitucionalización de los derechos sociales" (presentación del número monográfico Teoría y Derecho, no 9/2011 dedicado a “Los derechos sociales en tiempos de crisis”), en el que criticábamos la visión sesgada de las generaciones de derechos; advertíamos entonces que el proceso generacional fue a la inversa, en comparación con el ámbito constitucional, en el terreno internacional ${ }^{2}$, y que en este precisamente se mencionó la dignidad por primera vez asociada a los derechos humanos por referencia a los sociolaborales (Declaración de Filadelfia de la OIT de 1944). A tal efecto, analizábamos, en el Derecho constitucional comparado y en el Derecho internacional comparado de los derechos humanos, la "relación simbiótica entre los derechos sociales y los de libertad. Las ideas de justicia y de dignidad humana como fundamentos de los derechos sociales”3.

\section{La militancia continua a favor de los derechos sociales: la convicción acerca de un constitucionalismo social multinivel al alza}

Dicho lo anterior, la militancia a favor de los derechos ha sido continua en el cometido académico, científico y social del Prof. Terol, estando imbuido por una convicción constante acerca de lo que podríamos llamar un constitucionalismo social multinivel al

\footnotetext{
${ }^{1}$ Entre otros trabajos suyos en dicho ámbito: "Sobre la idea de medio ambiente perceptible en el Tratado por el que se establece una Constitución para Europa”, Revista de Derecho Político, nº 65, 2006, pp. 6190; "De la salubridad y comodidad de los vecinos al medio ambiente urbano", en Estudios sobre la Constitución Española: Homenaje al Profesor Jordi Solé Tura, vol. 2, 2008, pp. 1425-1440; “Sobre el estudio jurídico-constitucional del medio ambiente”, Revista de Derecho Político, $\mathrm{n}^{\circ}$ 75-75, 2009, pp. 517546; o “Aproximación al contenido de un derecho constitucional al medio ambiente”, Estudios de Deusto, vol. 59, no 12, 2011, pp. 169-208.

${ }^{2}$ Inicialmente, los derechos colectivos y de las minorías en el ámbito de la Sociedad de Naciones, luego los derechos socio-laborales en el seno de la OIT a partir de 1919 y, por último, la internacionalización de la protección de los derechos cívico-políticos a partir de la Segunda Guerra Mundial.

${ }^{3}$ En Teoría y Derecho. Revista de Pensamiento Jurídico, n 9, 2011, pp. 7-19.
} 
alza que impulsó con especial ahínco y compromiso desde la feliz iniciativa del lanzamiento del Foro Andaluz de los Derechos Sociales, en el que tanto y generoso juego nos ha brindado a la comunidad universitaria y a la sociedad civil para la procura de la justicia social y el respeto de la dignidad humana.

En efecto, en el marco de ese Foro, Manolo ha favorecido la producción de obras fundamentales, de autoría única o en coautoría, que siempre han estado impregnadas por el reto de dotar de efectividad a los derechos sociales reconocidos en la Constitución de 1978, teniendo presentes una serie de vectores, que me permitiría cifrar en tres:

$\left.1^{0}\right)$ La vigencia de la Constitución social actual (que él llamaba también “del bienestar") es susceptible de ser potenciada teniendo en mente nuestro constitucionalismo histórico en clave de progresividad, de tal modo que no únicamente ha puesto el acento en el, no por ostensible, menos recurrente constitucionalismo social de la Constitución republicana de 1931, sino en el realce de la igualdad y sus diversas manifestaciones en toda nuestra historia constitucional ${ }^{4}$.

$\left.2^{\circ}\right)$ Nuestra Constitucional social debe ser garantizada jurídicamente en el marco de un constitucionalismo multinivel presidido por el principio favor libertatis o pro personae, desde el nivel interno más cercano a la ciudadanía hasta el estándar internacional más elevado, de tal suerte que:

a) Los catálogos autonómicos de derechos sociales, sin ser catálogos constitucionales, tampoco podían quedar abocados a una mera consideración (parafraseando a Ferdinand Lassalle) como meros pedazos de papel, sino beneficiarse de las soluciones más favorables (con especial hincapié en la Carta Social Europea ${ }^{5}$ ) para contribuir a la realización material de la Constitución social ${ }^{6}$. Adicionalmente, el Prof. Terol, en clave de subsidiariedad, es sabido que prestó un especial interés al papel de las Administraciones locales y su cometido esencial en el favorecimiento de los derechos sociales: de hecho, recuerdo que en el I Foro Andaluz (mayo de 2006) me encomendó la

\footnotetext{
${ }^{4}$ A título de ejemplo, su libro La igualdad ilustrada y revolucionaria en la Constitución de 1812, Valencia, Tirant lo Blanch, 2012; o su trabajo "Sobre la igualdad en las Constituciones decimonónicas españolas posteriores a la de 1812”, en Constitución y democracia: ayer y hoy. Libro homenaje a Antonio Torres del Moral, Vol. 1, 2012, Madrid, Universitas/CEPC/UNED, pp. 717-772.

5 Sobre el particular, TEROL BECERRA, Manuel: "La España de los derechos sociales en las Europas vista desde las reformas estatutarias”, Revista Europea de Derechos Fundamentales, $\mathrm{n}^{\circ}$ 13, 2009, p. 129: "Conviene llamar la atención sobre la paradoja que significa el enorme esfuerzo realizado por las Comunidades Autónomas al reformar sus Estatutos de Autonomía para incluir en ellos las referidas enumeraciones de derechos sociales, aparentemente inspiradas, por cierto, en el catálogo de la CSE, con el escaso interés que viene en España mostrando la instancia central para comprometerse, sin reservas, con la CSE. Téngase en cuenta que España ha ratificado la versión de la CSE de 1961, así como el Protocolo de 1988 y el Protocolo de reforma de 1991, pero no el Protocolo adicional de 1995 ni la Carta revisada de 1996”.

${ }^{6}$ TEROL BECERRA, Manuel J.: “La solución más favorable a través del Estatuto andaluz”, Lex Social, $\mathrm{n}^{\circ}$ 2, 2014, pp. 1-23.
} 
ponencia "Los servicios sociales en España vistos desde Europa"7 para incidir en la trascendencia de las acciones públicas en ese nivel territorial y, con anterioridad, me había pedido en su condición de director de la revista Nuevas Políticas Públicas que reflexionara sobre esa asignatura pendiente que teníamos en España relativa a la no aceptación de la conocida como "Constitución Social de Europa” o "Pacto Europeo de Democracia Social” ${ }^{\text {. }}$

b) El reforzamiento de los estándares regionales y locales, del mismo modo que los estatales, deben estar necesariamente abiertos (como impone la propia Constitución en sus mandatos interpretativo y aplicativo de los arts. 10.2 y 93 a 96) a los parámetros europeos más favorables. En este punto, obviamente, conocida ha sido la debilidad del Prof. Terol por el Consejo de Europa como Europa de los Derechos Humanos (y dentro de ella, por la Carta Social Europea -CSE- y el Comité Europeo de Derechos Sociales -CEDS-) frente a la otra Europa de los Mercaderes. Son muchas las anécdotas y vivencias con Manolo; permítaseme mencionar telegráficamente algunas de ellas, que le dejaron desigual ilusión y (des)aliento:

-En su visión crítica de esas “dos Europas” y defendiendo con rotundidad el lugar central de la Carta Social Europa, con expresión lapidaria se refirió a la "Europa de los piratas” para criticar las medidas de austeridad impulsadas por la Troika desde la UE con motivo de un importante encuentro internacional en la sede del Comité económico, social y ambiental de Francia (París, septiembre de 2011) ${ }^{9}$, interpelando especialmente a algunos miembros presentes del Comité Económico y Social de la UE (que colaboraba en la organización del evento).

-Pudimos compartir momentos agradables en Estrasburgo con motivo del $50^{\circ}$ aniversario de la Carta de 1961, en octubre de 2011, en donde en el marco de una sesión del CEDS, bajo mi presidencia, invitamos formalmente a un intercambio a Manolo como coordinador para España y América Latina de la Red Académica sobre la Carta Social Europea y los Derechos Sociales (RACSE), así como a su Coordinador General JeanFrançois Akandji-Kombé y a Mohamed Amrani como promotor de la

\footnotetext{
${ }^{7}$ Véase en TEROL BECERRA, Manuel J. (Dir.): I Foro andaluz de los derechos sociales: los derechos sociales en el siglo XXI, Valencia, Tirant lo Blanch, Valencia, 2009.

${ }^{8}$ JIMENA QUESADA, Luis: "Retos pendientes del Estado social español: en especial, la ratificación de la Carta Social Europea revisada de 1996”, Nuevas Políticas Públicas (Anuario multidisciplinar para la modernización de las Administraciones Públicas, nº 2 (monográfico sobre Los derechos sociales), Sevilla, Junta de Andalucía/Instituto Andaluz de Administración Pública, 2006, pp. 41-70.

${ }^{9}$ Conferencia internacional “La Charte sociale du Conseil de l’Europe: 50 ans et après?”, organizada conjuntamente por el Consejo de Europa (Servicio de la Carta Social Europea), el Consejo económico, social y ambiental de Francia y el Comité Europeo Económico y Social, celebrada en París, en la sede del Consejo francés, el 23 de septiembre de 2011
} 
RACSE en nuestro vecino Marruecos. En contrapartida, recuerdo que vivió momentos tristes en octubre de 2014 con motivo del lanzamiento formal del "Proceso de Turín” en dicha ciudad, tanto porque realizó un gran esfuerzo físico para desplazarse (solo), como por no poder yo acompañarle por razones igualmente físicas $\mathrm{y}$, sobre todo, por su decepción al ver bloqueada su ilusión por ser miembro del CEDS en el que yo debía concluir mi mandato dos meses más tarde.

c) No obstante, Manolo

siempre ha seguido apostando por promover con firmeza la Carta Social y la jurisprudencia del CEDS, tanto en España y en Europa como en condiciones de enriquecimiento mutuo con otros continentes, especialmente en América y en África: en cuanto a lo primero, incluso en meses anteriores a su fallecimiento y pese a su delicada salud, no paraba de insistirme en que debíamos ir a México y a otros países para trabajar honestamente con nuestros colegas y amigos latinoamericanos en el ámbito de los derechos sociales ${ }^{10}$, lo cual lamentablemente no hemos podido llegar a desarrollar juntos (como es conocido, esa temática ha estado presente en su compromiso con buen número de direcciones de tesis doctorales latinoamericanas); en lo que atañe a lo segundo, todo reconocimiento será poco a su labor en su amado Marruecos, con actividades como el coloquio internacional organizado en octubre de 2013 en la Universidad Abdelmalek Essaadi de Tánger por el Foro Andaluz y la RACSE sobre “Les politiques d'austérité et les droits sociaux en Europe"11.

d) Al hilo de lo anterior, el Prof. Terol mostró asimismo su debilidad por la mundialización y universalización de los valores del constitucionalismo ${ }^{12}$ y, por ello mismo, mi contribución en el presente número monográfico de Lex Social en homenaje a él he querido que verse sobre "El Constitucionalismo Social y los Objetivos de Desarrollo Sostenible (ODS)”. Desde este punto de vista, aún me afloran charlas con él acerca del parámetro universal por excelencia en materia de derechos económicos, sociales y culturales (DESC), el Pacto DESC de 1966 y su Comité DESC, cabalmente a propósito de la utilidad que para desentrañar el contenido de los derechos sociales reconocidos en nuestra Constitución de 1978 presentan las Observaciones Generales de dicho Comité de la ONU. En este sentido, Manolo me confirió el honor de codirigir a su lado el Coloquio

\footnotetext{
${ }^{10}$ Con análisis crítico frente a enfoques trocados de demagogia y populismo, véase TEROL BECERRA, Manuel J.: El neoconstitucionalismo latinoamericano, Valencia, Tirant lo Blanch, 2015.

${ }^{11}$ En dicho coloquio, además de los colegas marroquíes y españoles que hicimos gala de lazos de amistad y buena vecindad mediterránea, participaron el Ex Presidente, el Vicepresidente y el Secretario Ejecutivo del CEDS, Jean-Michel Belorgey (a quien además brindamos un cálido homenaje), Petros Stangos y Régis Brillat, respectivamente.

12 TEROL BECERRA, Manuel J.: “Globalización versus Universalización constitucional en el Mediterráneo. Propuesta metodológica para un análisis de la diversidad”, Revista de Derecho Político, $\mathrm{n}^{\circ}$ 60, 2004, pp. 71-94.
} 
internacional sobre "Protección de derechos sociales" celebrado en Sevilla (los días 21 a 24 de septiembre de 2010), organizado por el Proyecto de Investigación de Excelencia de la Junta de Andalucía "La construcción del Estado Social en el ámbito autonómico y europeo", en el que participamos buena parte de quienes hoy aquí nos hemos congregado para rendirle tributo ${ }^{13}$ y que fraguó en esa obra colectiva (integrada por una treintena de capítulos) que es nuestro Tratado sobre protección de derechos sociales, publicado por Tirant lo Blanch en 2014.

\section{Y $3^{\circ}$ ) nuestra Constitucional social debe ser asimismo garantizada} económicamente 0 sostenida financieramente en ese mismo marco de constitucionalismo multinivel al alza, de modo que la sesgada correlación entre satisfacción de derechos sociales y cobertura económica revela un alto grado de insensibilidad anclado en una concepción restrictiva de los recursos disponibles que no atiende a las exigencias axiológicas contemporáneas de solidaridad internacional. Frente a ello, el Prof. Terol ha incidido en que los recursos existen y, en caso de dificultades financieras, el sentido de responsabilidad tiene que llevar al establecimiento de prioridades constitucionales, entre las cuales han de ocupar un lugar preferente los derechos sociales: así lo expresó en su libro Del Bienestar en la Constitución Española y de su implementación publicado en $2012^{14} \mathrm{y}$ ha sido el Leitmotiv en la última obra colectiva que ha dirigido (junto con Hamid), titulada Constitución financiera $y$ constitución social, publicada en $2018^{15}$, en la que contribuimos algunos de los aquí presentes y que es fruto de las actas de un congreso celebrado en abril de 2017 en esta misma Universidad ${ }^{16}$ : fue un encuentro de gran nivel y de entrañable recuerdo, pues

\footnotetext{
${ }^{13}$ Además de otros amigos y colegas de España y de otras partes de Europa, de África y de América, entre ellos quienes fueron Presidentes del Comité DESC y del Comité de Derechos Humanos de la ONU, los queridos y admirados Philippe Texier y Fabián Salvioli, respectivamente.

${ }^{14}$ TEROL BECERRA, Manuel J.: Del Bienestar en la Constitución Española y de su implementación, Valencia, Tirant lo Blanch, 2012, en especial el capítulo VI ("Crisis económica y prioridad de los derechos sociales”), p. 129: "Ninguna situación económica estable asegura la efectiva realización de los derechos sociales enunciados en las constituciones de nuestro entorno. Su sola mención constitucional no garantiza que se producirá una acción positiva estatal de índole prestacional y que se crearán los instrumentos procesales oportunos para reclamarla. Pero la fragilidad de tales derechos se percibe con mayor nitidez en una coyuntura de crisis económica. La escasez de recursos públicos disponibles puede mover a los poderes públicos a cuestionarse no ya la conveniencia de perfilar los todavía precisados de esa operación, sino también la oportunidad de suprimir o de suspender los ya concretizados o cuando menos de minorar las prestaciones ya decididas con relación a estos últimos. Es entonces, en definitiva, cuando se hace más evidente la necesidad de tutelar los derechos sociales todos y los prestacionales particularmente, así como de priorizar entre los mismos".

${ }^{15}$ TEROL BECERRA, Manuel J. y ADNANE RKIOUA, Abdelhamid (Dirs.): Constitución financiera y constitución social, Valencia, Tirant lo Blanch, 2018.

${ }^{16}$ Congreso sobre Constitución financiera vs. Constitución social. Redefinición del Estado autonómico y social a la luz de la cláusula de estabilidad presupuestaria Andaluz de Derechos Sociales, dirigido por Manuel Terol Becerra y organizado en el marco del Proyecto de Investigación del Ministerio de Economía y Competitividad con referencia DER2013-48327-C3-3-R en la Facultad de Derecho de la Universidad Pablo de Olavide de Sevilla los días 25 y 26 de abril de 2017.
} 
comprobamos una vez más la entereza física y la fuerza moral de Manolo pese a su deteriorado estado de salud, presidiendo y moderando en todo momento las dos jornadas y erigiéndose en gran valedor y guardián de los derechos sociales; a este respecto, el maestro Antonio Torres del Moral, por quien él profesaba y profesamos los aquí reunidos gran admiración, volvió a reiterar la propuesta de creación de una Cátedra Profesor Terol sobre derechos sociales en la UPO de la que lógicamente Manolo debía ser titular; desgraciadamente, no ha dado tiempo para ello en vida pero, cuando menos, me consta el empeño del Prof. Torres del Moral, que comparto y suscribo plenamente, de promover que se dedique a la memoria de Manolo un espacio visible en la UPO, como justo merecimiento y compensación a la visibilidad y proyección internacionales que ha dado él a esta institución universitaria, especialmente a través de su militancia y su compromiso universal a favor de los derechos sociales.

\section{El legado del Profesor Terol en la defensa de los derechos sociales: palabras para no concluir}

Llegados a este punto, quiero completar esta modesta presentación en homenaje al Profesor Terol con unas "palabras para no concluir", dado su legado impagable en la defensa de los derechos sociales. Efectivamente, nos deja los buenos momentos de amistad y buena vecindad vividos en torno a los encuentros (congresos y seminarios u otras actividades académicas como tesis doctorales, etc.) con la bandera y el telón de fondo de los derechos sociales. Con tal espíritu, el Foro Andaluz siempre nos quedará como foro de amistades y de múltiples culturas en torno a los derechos sociales; me viene a la memoria que en el I Foro Manolo Terol hizo buena una expresión negativa, acuñando el término "hooligans" de los derechos sociales.

Nos lega sus propias publicaciones y las que nos ha permitido encauzar a los demás en el terreno de los derechos sociales: a título ilustrativo y personal (permítaseme que lo haga así, pero a buen seguro que os sentiréis reflejados todas y todos los presentes), he tenido la suerte de participar junto a él, entre otras obras, en diversas monografías que recogen las ediciones del Foro Andaluz, desde el primero (celebrado en 2006) hasta el quinto (celebrado en 2011), o en la codirección del citado Tratado sobre Protección de Derechos Sociales; Manolo ha tenido a bien facilitarme y hacer el gran esfuerzo de honrarme con la redacción del breve prólogo de mi último libro, publicado en Tirant lo Blanch en 2017 (Devaluación y blindaje del Estado social y democrático de Derecho), o unos años antes presidir (en febrero de 2014) el tribunal que valoró la tesis doctoral realizada bajo mi dirección por Daría Terrádez Salom bajo el título La Carta Social Europea en el orden constitucional español, publicada en 2018 (en Sevilla, en Athenaica Ediciones Universitarias), gracias a los buenos oficios del querido amigo y colega Luis Gordillo. De ese tribunal formaron parte asimismo los Profesores Mohamed Amrani y Carmen 
Salcedo Beltrán. Justamente, en la Profesora Salcedo confió el Profesor Terol la codirección de la revista Lex Social, uno de los grandes legados de Manolo que está continuando y realzando Carmen con toda solvencia, solidez y ostensible éxito a tenor de los indicios de calidad e impacto que está ganando la publicación.

En este contexto, en suma, el Prof. Terol nos transmite su pasión por el Consejo de Europa y la Carta Social Europea y su deseo de haber aprendido, hecho y vivido incluso más ${ }^{17}$; sus constructivas críticas y reticencias hacia la UE; su pesadumbre hacia una doctrina constitucionalista muy deudora de infravalorados principios rectores de la política social y económica ${ }^{18}$; y su espíritu luchador, en definitiva, para que los derechos sociales no sufran de una posición relegada, de una dependencia y de una vulnerabilidad a las que él mismo siempre ha hecho frente ${ }^{19}$.

Mi querido y recordado Manolo, que esa fuerza y ese espíritu batallador y militante tuyos a favor de los derechos sociales siempre nos acompañen.

\footnotetext{
${ }^{17}$ Por ejemplo, el Prof. Terol se habría congratulado de ver el primer intento de un Gobierno español, a inicios de febrero de 2019, de someter a ratificación de las Cortes Generales la versión revisada (1996) de la Carta Social Europea, finamente frustrado tras la disolución anticipada de las Cámaras y la convocatoria de elecciones generales para el 28 de abril de 2019. O habría compartido con algunos de nosotros el regocijo de comprobar cómo nuestra Jurisdicción Constitucional ha consagrado, por fin (STC 140/2018, de 20 de diciembre, FJ 6), el control de convencionalidad, avalando así simple y llanamente la coherencia de nuestro sistema de fuentes y la posición "vanguardista” en tal sentido de algunos órganos jurisdiccionales (especialmente, en el orden social) para dotar de efectividad a los derechos socio-laborales frente a las reticencias precedentes y persistentes de buena parte de la judicatura y de la doctrina constitucionalista.

${ }^{18}$ Véase TEROL BECERRA, Manuel J.: "Treinta años de desarrollo constitucional y legislativo de los derechos sociales: derechos ciudadanos y principios rectores", en Derechos sociales y principios rectores: Actas del IX Congreso de la Asociación de Constitucionalistas de España, Valencia, Tirant lo Blanch, 2012, pp. 45-86.

${ }^{19}$ De hecho, las situaciones de vulnerabilidad estuvieron siempre presentes con carácter transversal en las cinco ediciones del Foro Andaluz de Derechos Sociales y ocuparon monográficamente tres de ellas, concretamente la segunda, la tercera y la cuarta, cuyas actas quedan reflejadas en los siguientes libros bajo la dirección del Profesor Terol Becerra: Pobreza y Exclusión: II Foro Andaluz de los Derechos Sociales, Valencia, Tirant lo Blanch, 2009; Diversidad y Ciudadanía: III Foro Andaluz de los Derechos Sociales, Valencia, Tirant lo Blanch, 2010, e Igualdad e integración: IV Foro Andaluz de los Derechos Sociales, Valencia, Tirant lo Blanch, 2011.
} 